\title{
Delays in insulin signaling towards glucose disposal in human skeletal muscle
}

\author{
T Grimmsmann, K Levin ${ }^{1}$, M M Meyer, H Beck-Nielsen ${ }^{1}$ \\ and $\mathbf{H} \mathbf{H}$ Klein \\ Medizinische Klinik 1, Medizinische Universität zu Lübeck, Ratzeburger Allee 160, D-23538 Lübeck, Germany \\ ${ }^{1}$ Diabetes Research Center, Odense University Hospital, DK-5000, Denmark \\ (Requests for offprints should be addressed to H H Klein; Email: klein@medinf.mu-luebeck.de)
}

\begin{abstract}
We explored whether the delay that occurs between a rise in plasma insulin and the increase of glucose disposal occurs before, at, or downstream of steps that are believed to be part of the insulin signaling cascade. Skeletal muscle biopsies were obtained from 16 nondiabetic subjects before, and 20 and $180 \mathrm{~min}$ after plasma insulin levels had been augmented in euglycemic hyperinsulinemic glucose clamps. Although plasma insulin had reached $98 \%$ of its final concentration within $10 \mathrm{~min}$, insulin receptor kinase (IRK) activity, p85 associated with insulin receptor substrate-1 (IRS-1), IRS-1-associated
\end{abstract}

phosphatidylinositol 3-kinase (PI3K) activity, and $\mathrm{Thr}^{308}$ protein kinase $\mathrm{B}(\mathrm{PKB})$ phosphorylation in the muscle biopsies at $20 \mathrm{~min}$ had reached only $60,48,34$ and $47 \%$ respectively of those at $180 \mathrm{~min}$. This suggests a delay before the level of IRK and little or no delay between IRK and PKB activation. The observation that glycogen synthase activity and glucose disposal at $20 \mathrm{~min}$ had both only reached $25 \%$ of the respective values at 180 min suggests an additional delay downstream of the investigated signaling steps.

Journal of Endocrinology (2002) 172, 645-651

\section{Introduction}

When plasma insulin concentration is increased in euglycemic hyperinsulinemic glucose clamps, the rate of activation of glucose disposal is substantially slower than the rise in plasma insulin (Prager et al. 1986, Freidenberg et al. 1994). There is evidence that this delay is more pronounced in type 2 diabetic and obese subjects compared with lean subjects (Nolan et al. 1994), and it may therefore be of clinical importance. At least a part of the delay appears to be due to the time needed for the transport of insulin across the endothelial barrier. Endothelial cells possess insulin receptors that bind the insulin and transport it unidirectionally into the interstitial space (Jialal et al. 1984, King \& Johnson 1985). This process is relatively slow, and is mirrored by a delayed increase in lymph insulin concentration measured in the thoracic duct (Rasio et al. 1967), by lymphatic cannulation (Castillo et al. 1994) or microdialysis (Jansson et al. 1993). Moreover, activation of insulin receptor kinase (IRK) has been described to be substantially slower than the rise in plasma insulin (Freidenberg et al. 1994).

In the present study we investigated whether this proposed delay between plasma and lymph insulin is also reflected in a slower activation of the insulin signaling cascade, and whether additional delays occur within the known insulin signaling cascade (Taha \& Klip 1999) or downstream of these known signaling steps. Euglycemic hyperinsulinemic glucose clamps were performed in 16 nondiabetic subjects and muscle biopsies obtained before, and 20 and $180 \mathrm{~min}$ after the start of the insulin infusions. These biopsies were analyzed for IRK activity, association of p85-phosphatidylinositol 3-kinase subunit with insulin receptor substrate-1 (IRS-1), IRS-1associated phosphatidylinositol 3-kinase (PI3K) activity, $\mathrm{Thr}^{308}$-phosphorylation of protein kinase $\mathrm{B}(\mathrm{PKB})$, and glycogen synthase activity.

\section{Materials and Methods}

\section{Human subjects}

Muscle biopsies from 16 Caucasian volunteers (for subject characteristics, see Table 1) were analyzed. None of the subjects suffered from diabetes as evaluated by an oral glucose tolerance test or any other disease as evaluated by clinical investigation and standard laboratory assessments, with the exception that two of the subjects continued to receive antihypertensive medication throughout the study. Prior to entry into the study, the purpose and risks of the experimental protocol were explained carefully to all of the volunteers and informed written consent was 
Table 1 Subject characteristics: laboratory data were analysed in blood drawn under fasting conditions in the morning 2 days before the clamp. Data represent means \pm S.E.M.

$n$ (male/female)
Age $($ years)
BMI $\left(\mathrm{kg} / \mathrm{m}^{2}\right)$
Fat-free mass $(\mathrm{kg})$
Fat mass $(\mathrm{kg})$
Fasting insulin $(\mathrm{pM})$
Fasting glucose $(\mathrm{mM})$
Free fatty acids $(\mu \mathrm{M})$
Triglycerides $(\mathrm{mM})$
Cholesterol $(\mathrm{mM})$
HDL $(\mathrm{mM})$
LDL $(\mathrm{mM})$

\begin{tabular}{r}
\hline $16(15 / 1)$ \\
$48 \cdot 6 \pm 3 \cdot 4$ \\
$30 \cdot 8 \pm 0 \cdot 8$ \\
$59 \cdot 9 \pm 2 \cdot 3$ \\
$38 \cdot 0 \pm 2 \cdot 7$ \\
$46 \cdot 4 \pm 6 \cdot 7$ \\
$5 \cdot 6 \pm 0 \cdot 1$ \\
$377 \cdot 0 \pm 40$ \\
$1 \cdot 4 \pm 0 \cdot 2$ \\
$6 \cdot 0 \pm 0 \cdot 2$ \\
$1 \cdot 3 \pm 0 \cdot 1$ \\
$4 \cdot 1 \pm 0 \cdot 2$
\end{tabular}

BMI, body mass index; HDL, high-density lipoprotein; LDL, low-density lipoprotein.

obtained. The protocol was approved by the local ethical committee and was in accordance with the Helsinki II Declaration.

\section{Euglycemic hyperinsulinemic glucose clamps}

Subjects were admitted to the clinical research center at $0800 \mathrm{~h}$ and intravenous catheters inserted for infusion of insulin and glucose into the antecubital vein. Blood samples for plasma glucose analyses were drawn from a catheter of the dorsal wrist vein of the opposite arm. During the study, the subjects remained in a supine position with the hand designated for collection of blood samples placed and maintained in a heated Plexiglas box for arterialization of venous blood (McGuire et al. 1976). After a 30-min relaxation period, at time zero, a surfaceadjusted priming dose of $3-{ }^{3} \mathrm{H}$ glucose was given $\left(14 \mu \mathrm{Ci} / \mathrm{m}^{2}\right.$; DuPont-New England Nuclear, Boston, MA, USA) followed by a continuous infusion of $3-{ }^{3} \mathrm{H}$ glucose $\left(0 \cdot 14 \mu \mathrm{Ci} / \mathrm{min}\right.$ per $\left.\mathrm{m}^{2}\right)$, which was continued throughout the study periods. After a 120-min basal tracer equilibration period, insulin (Actrapid, Novo-Nordisk, Bagsvaerd, Denmark) was infused at a rate of $40 \mathrm{mU} / \mathrm{m}^{2}$ per $\min$ for $180 \mathrm{~min}$ and euglycemia $(5.9 \pm 0.1 \mathrm{mM})$ maintained using a variable infusion of $18 \%$ glucose. In order to keep plasma specific activity constant at the basal level during the clamp, $3{ }^{3} \mathrm{H}$ glucose was added to the glucose infusate (HOT-GINF) as previously described (Hother-Nielsen et al. 1995). The glucose disposal rate was calculated from the plasma concentrations of tritiated glucose and plasma glucose using Steele's non-steady-state equations (Steele 1959). In these calculations, the distribution volume of glucose was taken as $200 \mathrm{ml} / \mathrm{kg}$ body weight and the pool fraction as $0 \cdot 65$. Body composition was estimated with the bioimpedance method using the formula of Kushner (Kushner \& Schoeller 1986). Plasma glucose was measured at bedside on a Beckman glucose analyzer (Beckman Instruments, Fullerton, CA, USA) by the glucose oxidase method. Plasma insulin blood samples were immediately centrifuged at $4{ }^{\circ} \mathrm{C}$ and stored at $-20{ }^{\circ} \mathrm{C}$ for later analysis by two-site time-resolved immunofluorimetric assay. Triglyceride was measured by an enzymatic colorimetric method, as was free fatty acid (Wako Chemicals, Neuss, Germany).

\section{Muscle biopsies}

Percutaneous $M$. vastus laterialis biopsies were taken under local anesthesia (2\% lidocaine without epinephrine) $20 \mathrm{~cm}$ above the knee using the Bergstrom method (Bergstrom $1975)$ at the end of the basal period $\left(t_{0}\right)$, after $20 \mathrm{~min}\left(t_{20}\right)$, and again $3 \mathrm{~h}\left(\mathrm{t}_{180}\right)$ after the beginning of the insulin infusion. Biopsies were immediately frozen and for subsequent analytical procedures approximately $50 \mu \mathrm{g}$ frozen tissue was homogenized at $4{ }^{\circ} \mathrm{C}$ in $500 \mu$ solubilization buffer $(8 \mathrm{mM}$ EDTA, $20 \mathrm{mM}$ Hepes, 1\% IGEPAL, $530 \mathrm{mM} \mathrm{NaF}, 30 \mathrm{mM}$ sodium pyrophosphate, $7 \mathrm{mM}$ sodium vanadate, $2 \mathrm{mM}$ dichloroacetic acid, $9 \mathrm{mM}$ PMSF, $21 \mathrm{mM}$ benzamidine, $5 \mu \mathrm{M}$ leupeptin, $4 \mu \mathrm{M}$ pepstatin, and $10 \mu \mathrm{g} / \mu \mathrm{l}$ aprotinin, $\mathrm{pH} \mathrm{7.4).} \mathrm{After} 20 \mathrm{~min}$, detergent-insoluble material was removed by centrifugation $\left(12000 \mathrm{~g}, 20 \mathrm{~min}, 4^{\circ} \mathrm{C}\right)$ and the protein concentration measured using protein-dye binding assay (BioRad, Munich, Germany).

\section{$I R K$ and binding activities}

These were measured essentially as published (Klein et al. 1993, Krützfeldt et al. 2000). Muscle sample lysates $(300 \mu \mathrm{g}$ protein) were added to microwells coated with anti-insulin receptor antibody (ATCC, Rockville, MD, USA) for $16 \mathrm{~h}$ at $4{ }^{\circ} \mathrm{C}$. The wells were washed and receptor-mediated ${ }^{32} \mathrm{P}$ incorporation into recombinant IRS-1 (17 nM; Upstate Biotechnology Inc., New York, NY, USA) measured at $120 \mathrm{nM}{ }^{32} \mathrm{P}-\mathrm{ATP} .{ }^{125} \mathrm{I}-\mathrm{Tyr}-$ $\mathrm{A}^{14}$ ]-Monoiodoinsulin (Amersham-Pharmacia, Freiburg, Germany) binding to immobilized insulin receptors was also measured in the wells as described (Klein et al. 1993). Insulin binding capacity was defined as the amount of specifically bound insulin at a concentration of $8.7 \mathrm{nM}$ (Klein et al. 1995). IRK activity was expressed as amol phosphate transferred into IRS-1 per min per fmol insulin binding capacity.

\section{PI3K activity}

Solubilized muscle $(260 \mu \mathrm{g}$ protein) was added to microwells coated with anti-IRS-1 antibody (Upstate Biotechnology Inc.) that had been prepared as described (Krützfeldt et al. 2000). After $16 \mathrm{~h}$ at $4{ }^{\circ} \mathrm{C}$, wells were washed and $10 \mu \mathrm{g}$ phosphatidylinositol (Sigma, Deisenhofen, Germany) in $30 \mu 110 \mathrm{mM}$ Tris, $100 \mathrm{mM}$ 
$\mathrm{NaCl}, 1 \mathrm{mM}$ EDTA, and $15 \mathrm{mM} \mathrm{MgCl}$, pH 7.5 added. The phosphorylation reaction was started by the addition of $5 \mu \mathrm{l}$ of a solution that contained $720 \mu \mathrm{M}{ }^{32} \mathrm{P}$-ATP $(12.5 \mu \mathrm{Ci} / \mathrm{mmol}$; NEN, Dreieich, Germany). After $1 \mathrm{~h}$ at room temperature the reaction was stopped by the addition of $20 \mu \mathrm{l} 25 \% \mathrm{HCl}$ and $95 \mu \mathrm{l}$ of methanolchloroform (1:1). The organic phase was extracted and applied to a silica gel thin-layer chromatography plate. Phosphatidylinositol-3 phosphorylation was then determined using a phosphoimager.

\section{Glycogen synthase activity}

Extraction of muscle samples and assays for glycogen synthase were performed as previously described (Vaag et al. 1992). Briefly, glycogen synthase activity was assayed in the presence of a near physiological concentration of glucose-6-phosphate $(\mathrm{G} 6 \mathrm{P} ; 0.1 \mathrm{mM})$ and in the presence of $10 \mathrm{mM}$ G6P to determine maximal enzyme activity. The substrate concentration of uridine diphosphate glucose (UDPG) was $0.31 \mathrm{mM}$ and glycogen synthase activity was expressed as nmol of UDPG incorporated into glycogen per min per $\mu \mathrm{g}$ extract protein. Fractional velocities (FV) were calculated as the ratio between glycogen synthase activities assayed at $0 \cdot 1 \mathrm{mM}$ and $10 \mathrm{mM}$ G6P (FV 0-1).

\section{Immunoblots}

For the determination of the amount of IRS- 1 and IRS-1-associated p85, muscle sample lysates $(620 \mu \mathrm{g}$ protein) were incubated with anti-IRS-1 C-terminal antibody ( $2 \mu \mathrm{g}$; Upstate Biotechnology Inc.) coupled to protein G-agarose (Pierce, Rockford, USA). The agarose was washed, and bound proteins separated by SDS-PAGE. In order to express the IRS-1-associated amount of p 85 as percentage of its total amount, complete muscle lysates (25 $\mu \mathrm{g}$ protein) were separated on the same gels. Proteins were transferred to PVDF membranes or nitrocellulose (Millipore, Bedford, MA, USA) for IRS-1 or p85 blots respectively. Membranes were blocked overnight with PBS that contained 5\% skim milk. Proteins were then detected with anti-IRS-1 or anti-p85 antibodies (both Upstate Biotechnology Inc.). PKB phosphorylation was detected by immunoblotting of muscle sample lysates (155 $\mu \mathrm{g}$ protein) with an antibody against phosphorylated $\mathrm{Thr}^{308}$-PKB (BioLabs, Beverly, MT, USA).

\section{Data analysis}

Arbitrary units (AU) represent the ratio between the densitometric value measured at the respective time point $\left(t_{0}, t_{20}, t_{180}\right)$ and the mean of the densitometric values measured at all three time points of the same experiment. Statistical comparisons were carried out by one-way repeated measurements ANOVA and the

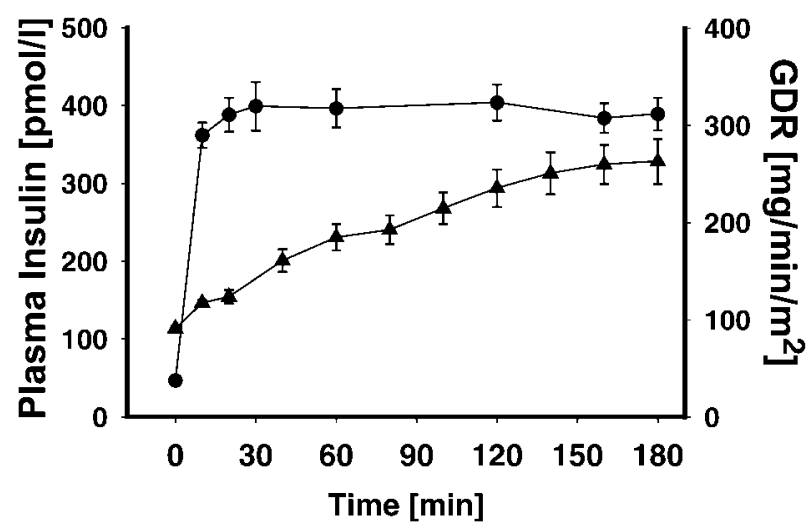

Figure 1 Insulin levels and glucose disposal rates (GDR). Euglycemic hyperinsulinemic clamps were performed in 16 obese volunteers. Shown are insulin levels and glucose disposal rates $\boldsymbol{\Delta}$. Results represent means \pm S.E.M.

Student-Newman-Keul post hoc test. Differences between the time points were considered as statistically significant if $P$ was $<0 \cdot 05$.

\section{Results}

After the start of the insulin infusion, plasma insulin levels increased rapidly and reached $99 \%$ of the value at $\mathrm{t}_{180}$ within $10 \mathrm{~min}$ (Fig. 1). In contrast, the increase in glucose disposal was slow, and at $t_{20}$ only $25 \%$ of the increase at $t_{180}$ had been reached (Fig. 1). To explore where this delay between plasma insulin levels and stimulation of glucose disposal occurs, the activation or phosphorylation of downstream signaling proteins was investigated (Fig. 2). IRK activity increased 4-2-fold within $180 \mathrm{~min}$ after the insulin infusion had been started. Compared with the quick increase of the plasma insulin concentration, IRK activation was slower. After $20 \mathrm{~min}$ the increase in IRK activity had reached only $60 \%$ of the increase after $180 \mathrm{~min}(P<0 \cdot 05)$. Our data therefore show that a delay occurs between the increase in plasma insulin levels and IRK activation. On the other hand, the increase of IRK activity within the first $20 \mathrm{~min}$ was more pronounced $(\sim 60 \%)$ than the increase in glucose disposal $(\sim 25 \%)$ in that time period. This indicates that a delay occurred not only between the increase in plasma insulin and IRK activation but also between IRK activation and the increase in glucose disposal.

For insulin-induced association of p85 with IRS-1, PI3K activation, and $\mathrm{Thr}^{308}$ phosphorylation of PKB 48, 34 or $47 \%$ respectively of the increases at $t_{180}$ had been reached at $\mathrm{t}_{20}$ (Fig. 2B-D). This indicates that, if at all, only slight delays occurred between IRK activation and these downstream signaling steps, and suggests that a major part of the delay observed between IRK activation and the increase in glucose disposal occurs downstream of the investigated signaling steps. 

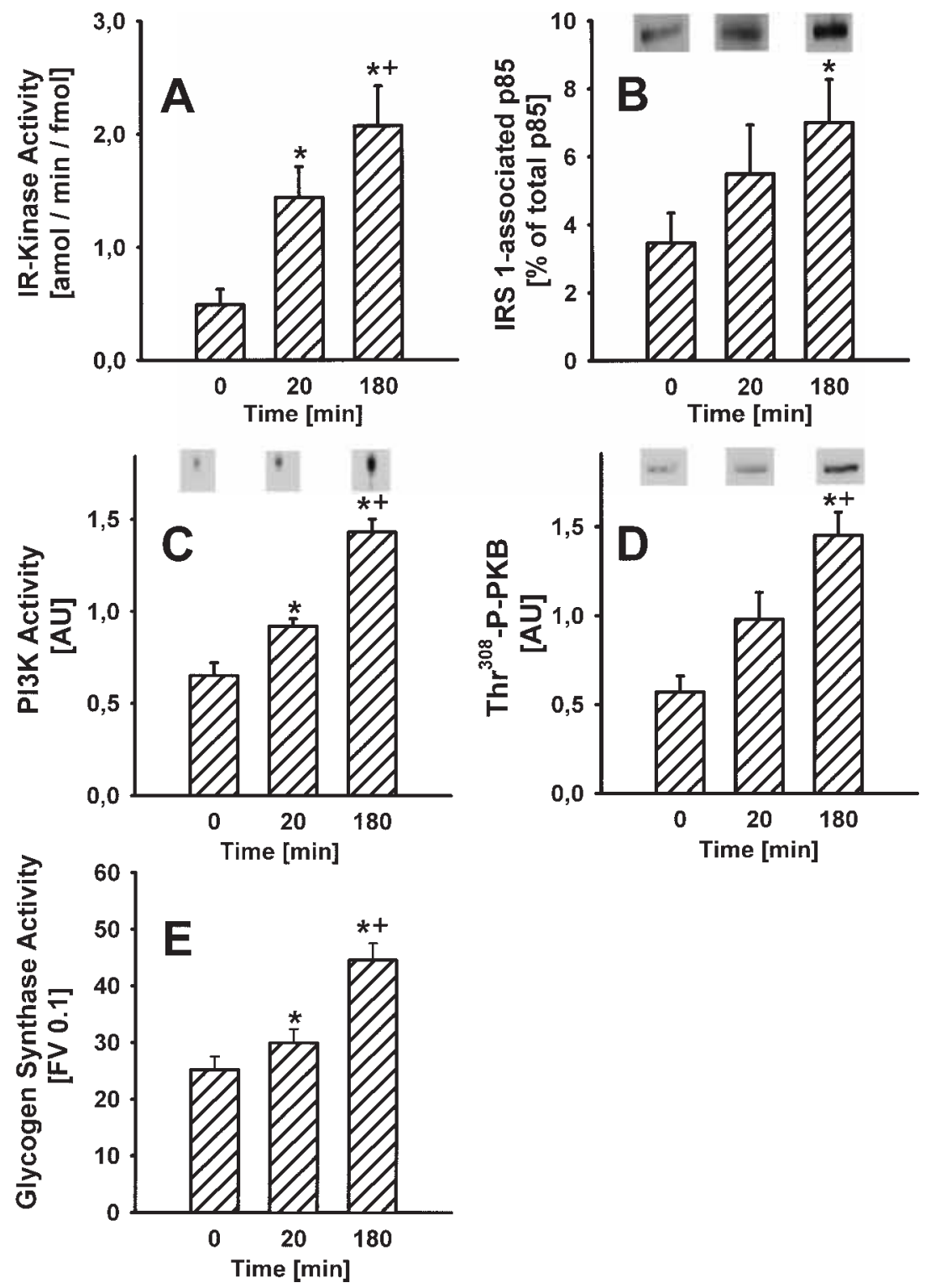

Figure 2 IRK activity, p85 associated with IRS-1, PI3K activity, Thr $^{308}$-phosphorylation of PKB and glycogen synthase activity. Muscle biopsies obtained at the indicated times after the initiation of the insulin infusion were solubilized, and parameters measured as described. (A) IRK activity determined as amol $\mathrm{P}$ transferred per min and per fmol insulin binding activity; (B) amount of p85 precipitated with anti-IRS-1 antibody as a percentage of the total p85; (C) IRS-1-associated PI3K activity (AU = arbitrary units); (D) Thr ${ }^{308}$ phosphorylation of PKB; (E) glycogen synthase activity expressed as fractional velocity (FV 0.1) as described. Data represent means \pm S.E.M., $n=12-16$. ${ }^{*} P<0 \cdot 05$ compared with corresponding basal;,$+ P<0 \cdot 05$ compared with corresponding 20 -min value.

Glycogen synthase is an important enzyme involved in non-oxidative glucose metabolism and, similar to the activation of glucose uptake, its activation is thought to be mediated, at least in part, by the PI3K/PKB pathway. At $\mathrm{t}_{20}$ only $25 \%$ of the increase in glycogen synthase activity at $t_{180}$ was reached (Fig. 2E), which was analogous to the findings for glucose disposal (Fig. 1). This indicates that activation of glycogen synthase was similarly delayed compared with the investigated signaling parameters as was glucose disposal.

Insulin stimulation did not alter the insulin-binding capacity, or the amounts of IRS-1 and p85, that were 
extracted per $\mu \mathrm{g}$ muscle protein. It also did not affect glycogen synthase activity at $10 \mathrm{mM}$ G6P, indicating that the amount of the enzyme did not change (data not shown).

\section{Discussion}

The stimulation of glucose disposal in response to an increase of the plasma insulin level has been found to be substantially delayed in previous studies (Prager et al. 1986, Freidenberg et al. 1994) and the present study, and it has been proposed that differences in this delay could play a role in the pathogenesis of type 2 diabetes (Ciaraldi et al. 1991, Nolan et al. 1994). Here we describe that a part of this delay occurs already between the increase in plasma insulin and the activation of IRK. This delay is most likely almost exclusively due to the time needed for the transcapillary transport of insulin since in isolated adipocytes (Klein et al. 1986) or cultured human muscle cells (Krützfeldt et al. 2000) insulin-stimulated IRK activation occurs within seconds and almost parallels receptor occupancy. The finding of a delayed IRK activation is therefore consistent with previous studies that showed delayed increases in lymphatic insulin concentration compared with plasma insulin concentration (Rasio et al. 1967, Yang et al. 1989, Jansson et al. 1993, Castillo et al. 1994). It is also consistent with previous data where the time course of IRK activation was measured in human skeletal muscle (Freidenberg et al. 1994, Wojtaszewski et al. 1997, 2000). Compared with our study, Freidenberg et al. (1994) observed sufficient IRK activation only at plasma insulin concentrations > $2000 \mathrm{pM}$, and delays observed at such high insulin concentrations may not reflect the physiological in vivo situation. Wojtaszewski et al. $(1997,2000)$ also found that IRK activity tended to increase further after steady-state insulin levels had been reached; this was, however, not significant. Our present study is therefore consistent with these previous studies and adds the information that IRK activation at insulin levels within, or close to, the physiological range is in fact significantly slower than the rise in plasma insulin levels.

Although IRK activation was delayed compared with the rise in plasma insulin levels, its activation was substantially more rapid than the stimulation of glucose disposal and the activation of glycogen synthase, suggesting that further delays occur downstream of the IRK. Association of $\mathrm{p} 85$ with IRS-1, IRS-1-associated PI3K activity, and $\mathrm{Thr}^{308}$-phosphorylation of PKB were, however, if at all, only slightly delayed compared with the activation of IRK, which suggests that the major delay between IRK activation and the effects of insulin on glucose uptake and glycogen synthesis occurs downstream from PI3K and/or PKB. The notion that a slight delay might occur between IRK and PI3K would be consistent with findings in human muscle strips where IRK activity tended to reach maximal levels slightly earlier than IRS-1-associated PI3K activity (Goodyear et al. 1995, Krook et al. 2000). With respect to the temporal relationship between PI3K activation and $\mathrm{PKB}$ phosphorylation in skeletal muscle, data in the literature are fairly contradictory. In isolated rat soleus muscle, PI3K activity was reached within 3 min whereas PKB phosphorylation needed $20 \mathrm{~min}$ to reach maximal levels (Song et al. 1999). A slight delay between PI3K activation and PKB phosphorylation was also found in cultured human muscle cells (Krützfeldt et al. 2000); the approximate 2-min delay may, however, not be detectable in an in vivo situation. In contrast, studies in isolated human skeletal muscle strips have revealed a similar or even slightly faster PKB phosphorylation (maximal after $\approx 8 \mathrm{~min}$ (Zierath et al. 2000)) than PI3K activation (maximal after 8-15 min (Krook et al. 2000)). Finally, in an investigation with skeletal muscle biopsies that were obtained during hyperinsulinemic euglycemic glucose clamps as in our study, a substantially more rapid $\mathrm{Ser}^{473}$ PKB phosphorylation and glycogen synthase activation (Wojtaszewski et al. 2000) than PI3K activation was found (Wojtaszewski et al. 1997). Wojtaszewski et al. concluded from their data that a limited activation of PI3K may be sufficient to maximally stimulate PKB or that mechanisms alternative to PI3K may regulate insulin stimulation of PKB. Such hypotheses are not required for the interpretation of our data that, most consistent with the data obtained with the isolated human skeletal muscle strips, show an almost parallel activation of PI3K and phosphorylation of $\mathrm{PKB}$. With respect to the discrepancy between Wojtaszewski et al.'s data and ours it is, however, possible that, due to a different study design, insulinstimulated PI3K activity levels were higher in their study and therefore, in contrast to our study, exceeded a level required for maximal PKB phosphorylation. In this context, it may also be of importance that our subjects were more obese than those studied by Wojtaszewski et al. In any case, our data indicate that, even if a slight delay in insulin signaling had occurred between IRK and PI3K or $\mathrm{PKB}$, this would not account for the delay that we observed between IRK activation and the stimulation of glucose disposal and glycogen synthase. Our data therefore suggest that the major delay between IRK activation and the insulin effects on glucose uptake and glycogen synthesis occurs downstream from PI3K and/or PKB. Moreover, the fact that the increase in glucose disposal and the covalent activation of glycogen synthase, as measured in our study, were similarly delayed suggests that downstream signaling towards these parameters might involve common signaling steps that are responsible for both delays.

At first sight, the concept that an additional delay occurs downstream of PI3K and PKB activation appears to be in partial contrast to data by Freidenberg et al. (1994) and Nolan et al. (1994), who showed comparable or even faster increases of glucose disposal compared with IRK 
activation. It must be considered, however, that plasma insulin concentrations during the clamps were considerably higher $(\approx 1800 \mathrm{pM})$ in these studies than in our study $(\approx 400 \mathrm{pM})$. It is likely that at high insulin concentrations a delay that occurs between plasma insulin levels and IRK activation does not cause a similar delay in the activation of glucose disposal. This is because submaximal IRK activities already maximally stimulate glucose disposal ('spare kinase' (Freidenberg et al. 1991)), and therefore the level of kinase activity needed to activate glucose disposal is reached more quickly at higher insulin concentrations (Freidenberg et al. 1994). Consistent with this view, activation of glucose disposal, expressed as percentage of its maximal response, occurs more rapidly at higher insulin concentrations (Prager et al. 1986), and glucose disposal was activated even faster than IRK in the study by Freidenberg et al. (1994). Taking these findings together, it is therefore conceivable that at the high insulin concentrations used in the studies by Freidenberg et al. (1994) and Nolan et al. (1994) the delay between plasma insulin levels and IRK activation contributed only little to the overall delay between plasma insulin levels and stimulation of glucose disposal, and that this latter delay was in fact caused predominantly by delays downstream of IRK activation.

The notion that there is a delay between IRK activation and stimulation of glucose disposal in human skeletal muscle is also consistent with findings in isolated human adipocytes. In these cells, complete activation of the insulin receptor occurred within seconds (Brillon et al. 1988), but half-maximal glucose uptake was only reached after 9 or $15 \mathrm{~min}$ in adipocytes from lean or obese subjects respectively (Molina et al. 1989, Ciaraldi et al. 1991). Moreover, since an even more pronounced delay was observed in isolated adipocytes from type 2 diabetic subjects (half-maximal effect at $23 \mathrm{~min}$ ), a pathophysiological role for this delay has been suggested (Ciaraldi et al. 1991).

In summary, our data suggest that the delay between the increase in plasma insulin and stimulation of glucose disposal is caused by the time needed for insulin to reach the interstitial space, and an additional delay downstream of IRK activation. Little or nothing of this delay appears to occur between the activation of IRK and the activation of PI3K or $\mathrm{Thr}^{308}$-phosphorylation of PKB. The fact that the increases in glucose disposal and the covalent activation of glycogen synthase were similarly delayed compared with the measured insulin signaling parameters may suggest that these delays occur at shared downstream signaling steps.

\section{Acknowledgements}

We gratefully acknowledge the superb technical assistance of A Eirich. This work was supported in part by grants from the Deutsche Forschungsgemeinschaft (KL 503/7-3 to HHK) the German Diabetes Association (HHK), the Danish Diabetes Association (KL, HBN), the Novo Nordisk Foundation (KL), and the Institute of Clinical Research, Odense University Hospital (HBN).

\section{References}

Bergstrom J 1975 Percutaneous needle biopsy of skeletal muscle in physiological and clinical research. Scandinavian Journal of Clinical and Laboratory Investigation 35 609-616.

Brillon DJ, Henry RR, Klein HH, Olefsky JM \& Freidenberg G 1988 Functional and structural differences in human and rat-derived insulin receptors: characterization of the $\beta$-subunit kinase activity. Endocrinology 123 1837-1847.

Castillo C, Bogardus C, Bergman RN, Thuillez P \& Lillioja S 1994 Interstitial insulin concentrations determine glucose uptake rates but not insulin resistance in lean and obese men. Journal of Clinical Investigation 93 10-16.

Ciaraldi TP, Molina JM \& Olefsky JM 1991 Insulin action kinetics in adipocytes from obese and noninsulin-dependent diabetes mellitus subjects: identification of multiple cellular defects in glucose transport. Journal of Clinical Endocrinology and Metabolism 72 876-882.

Freidenberg G, Suter S, Henry RR, Reichart D \& Olefsky JM 1991 In vivo stimulation of the insulin receptor kinase in human skeletal muscle. Correlation with insulin-stimulated glucose disposal during euglycemic clamp studies. Journal of Clinical Investigation $\mathbf{8 7}$ 2222-2229.

Freidenberg G, Suter S, Henry RR, Nolan JJ, Reichart D \& Olefsky JM 1994 Delayed onset of insulin activation of the insulin receptor kinase in vivo in human skeletal muscle. Diabetes 43 118-126.

Goodyear LJ, Giorgino F, Sherman LA, Carey J, Smith RJ \& Dohm GL 1995 Insulin receptor phosphorylation, insulin receptor substrate-1 phosphorylation, and phosphatidylinositol 3-kinase activity are decreased in intact skeletal muscle strips from obese subjects. Journal of Clinical Investigation 95 2195-2204.

Hother-Nielsen O, Henriksen JE, Staehr P \& Beck-Nielsen H 1995 Labelled glucose infusate technique in clamp studies. Is precise matching of glucose specific activity important? Endocrinology and Metabolism 2 275-287.

Jansson PAE, Fowelin JP, von Schenck HP, Smith UP \& Lönnroth PN 1993 Measurement by microdialysis of the insulin concentration in subcutaneous interstitial fluid. Diabetes 42 1469-1473.

Jialal I, King GL, Buchwald S, Kahn CR \& Crettaz M 1984 Processing of insulin by bovine endothelial cells in culture. Diabetes 33 794-800.

King GL \& Johnson SM 1985 Receptor-mediated transport of insulin across endothelial cells. Science 227 1583-1586.

Klein HH, Freidenberg G, Kladde M \& Olefsky JM 1986 Insulin activation of insulin receptor tyrosine kinase in intact rat adipocytes. Journal of Biological Chemistry 261 4691-4697.

Klein HH, Kowalewski B, Drenckhan M, Neugebauer S, Matthaei S \& Kotzke G 1993 A microtiter well assay system to measure insulin activation of insulin receptor kinase in intact human mononuclear cells. Diabetes 42 883-890.

Klein HH, Vestergaard H, Kotzke G \& Pedersen O 1995 Elevation of serum insulin concentration during euglycemic hyperinsulinemic clamp studies leads to similar activation of insulin receptor kinase in skeletal muscle of subjects with and without NIDDM. Diabetes 44 1310-1317.

Krook A, Björnholm M, Galuska D, Jiang XJ, Fahlman R, Myers MG Jr, Wallberg-Henriksson H, Zierath JR 2000 Characterization of signal transduction and glucose transport in skeletal muscle from type 2 diabetic patients. Diabetes 49 284-292. 
Krützfeldt J, Kausch C, Volk A, Klein HH, Rett K, Haring HU, Stumvdl M 2000 Insulin signaling and action in cultured skeletal muscle cells from lean healthy humans with high and low insulin sensitivity. Diabetes 49 992-998.

Kushner RF \& Schoeller DA 1986 Estimation of total body water by bioelectrical impedance analysis. American Journal of Clinical Nutrition 44 417-424.

McGuire EA, Helderman JH, Tobin JD, Andres R \& Berman M 1976 Effects of arterial versus venous sampling on analysis of glucose kinetics in man. Journal of Applied Physiology 41 565-573.

Molina JM, Ciaraldi TP, Brady D \& Olefsky JM 1989 Decreased activation rate of insulin-stimulated glucose transport in adipocytes from obese subjects. Diabetes 38 991-995.

Nolan JJ, Freidenberg G, Henry RR, Reichart D \& Olefsky JM 1994 Role of human skeletal muscle insulin receptor kinase in the in vivo insulin resistance of noninsulin-dependent diabetes mellitus and obesity. Journal of Clinical Endocrinology and Metabolism 78 471-477.

Prager R, Wallace P \& Olefsky JM 1986 In vivo kinetics of insulin action on peripheral glucose disposal and hepatic glucose output in normal and obese subjects. Journal of Clinical Investigation $\mathbf{7 8}$ 472-481.

Rasio EA, Hampers CL, Soeldner JS, Cahill GF Jr 1967 Diffusion of glucose, insulin, inulin, and Evans blue protein into thoracic duct lymph of man. Journal of Clinical Investigation 46 903-910.

Song XM, Ryder JW, Kawano Y, Chibalin AV, Krook A \& Zierath JR 1999 Muscle fiber type specificity in insulin signal transduction. American Journal of Physiology. Regulatory, Integrative and Comparative Physiology 277 R1690-R1696.
Steele R 1959 Influence of glucose loading and of injected insulin on hepatic glucose output. Annals of the New York Academy of Sciences $82420-430$

Taha C \& Klip A 1999 The insulin signaling pathway. Journal of Membrane Biology 169 1-12.

Vaag A, Henriksen JE \& Beck-Nielsen H 1992 Decreased insulin activation of glycogen synthase in skeletal muscles in young nonobese Caucasian first-degree relatives of patients with non-insulin-dependent diabetes mellitus. Journal of Clinical Investigation 89 782-788.

Wojtaszewski JFP, Hansen BF, Kiens B \& Richter EA 199 Insulin signaling in human skeletal muscle - time course and effect of exercise. Diabetes 46 1775-1781.

Wojtaszewski JFP, Hansen BF, Gade J, Kiens B, Markuns JF, Goodyear LJ, Richter EA 2000 Insulin signaling and insulin sensitivity after exercise in human skeletal muscle. Diabetes 49 325-331.

Yang YJ, Hope ID, Ader M \& Bergman RN 1989 Insulin transport across capillaries is rate limiting for insulin action in dogs. Journal of Clinical Investigation 84 1620-1628.

Zierath JR, Krook A \& Wallberg-Henriksson H 2000 Insulin action and insulin resistance in human skeletal muscle. Diabetologia $\mathbf{4 3}$ $821-835$

Received 15 November 2001

Accepted 22 November 2001 